\title{
Leaching of Lead and Copper by Citric Acid from Direct-to-Blister Copper Flash Smelting Slag
}

\author{
Krzysztof Gargul, Piotr Jarosz, Stanisław Małecki
}

AGH University of Science and Technology, Faculty of Non-ferrous Metals, al. Mickiewicza 30, 30-059 Kraków

Correspondence: krzygar@agh.edu.pl; Tel.: +48 126172646

\begin{abstract}
:
Direct-to-blister copper flash smelting slag contains up to $14 \%$ of copper and $2-4 \%$ of lead. Considering this fact, this material is subjected to the high-temperature reduction process. After this, converting process is performed on the $\mathrm{Cu}-\mathrm{Pb}-\mathrm{Fe}$ alloy being the product of decopperization process in electric furnace. An alternative to the presently used processing of flash smelting slag would be its hydrometallurgical treatment and selective recovery of $\mathrm{Pb}$ and $\mathrm{Cu}$. This paper presents the results of laboratory tests on flash smelting slag leaching with citric acid solutions. The experiments performed allowed to determine the process parameters at which the $\mathrm{Pb}$ concentration in the post-leaching sediment reached the value of $0.41-0.6 \%$ while the $\mathrm{Pb}$ content in flash smelting slag was $3.05 \%$. Analogous values for copper were $11.5-11.8 \%$ (after leaching) and $12.44 \%$ (before). Material after leaching in citric acid solutions can be processed, in the second step, using sulfuric acid solutions, and it could lead to the recovery of almost all copper contained in it.
\end{abstract}

Keywords: blister copper, flash smelting slag, citric acid, lead recovery, leaching

\section{Introduction}

As a result of melting of copper concentrates in direct-to-blister flash smelting furnace, a slag with a significant copper content (12-16\%) is obtained as one of the products. This is 25$30 \%$ of copper fed from the concentrate. The high content of copper in the slag results from the significant oxidation of the concentrate components in the furnace reaction shaft. This procedure is necessary to obtain a lead concentration below $0.3 \%$ in blister copper. Direct-toblister copper flash smelting slag also contains lead in an amount of $2.5-4 \%$ by mass. In order to recover copper as well as lead, the slag is subjected to the process of decopperization by the reduction of oxide metal compounds in the electric furnace in the presence of coke covering the surface of the slag bath. The products of the process are dust, waste slag, in which the concentration of copper is on average $0.6 \%, 0.7-1.2 \% \mathrm{~Pb}$ and $\mathrm{CuPbFe}$ alloy, which is then processed in the converter to obtain blister copper suitable for the fire refining process. The presence of lead in the alloy causes difficulties in further metallurgical processing and adversely affects the durability of metallurgical aggregates. In this work an attempt was made to find an alternative method of processing of flash smetling slag. Research has been carried out on the possibility of recovery of lead from slag by hydrometallurgical route in the process of leaching with the use of citric acid solutions. There are several advantages of the hydrometallurgical technology, namely the prospect of lower production costs, lower energy consumption and a higher recovery rate of lead from slag compared to conventional methods.

Citric acid $\left(\mathrm{C}_{6} \mathrm{H}_{8} \mathrm{O}_{7}\right.$ or $\left.\mathrm{C}_{6} \mathrm{H}_{8} \mathrm{O}_{7} \cdot \mathrm{H}_{2} \mathrm{O}\right)$ is a weak organic acid. Its structural formula is shown in Fig. 1. A number of works can be found in the literature in which the possibility of extracting metals from primary [1-4] and secondary [5-12] raw materials with the use of citric 
acid solutions was investigated. Research is also being conducted on the removal of heavy metals from the soil and ashes from waste incineration plants with citric acid [13-16]. Most of the tests carried out lead to high concentrations of leaching metals in solution under optimized conditions of the process. Citric acid in the aqueous environment dissociates according to reaction (1):

$2 \mathrm{C}_{6} \mathrm{H}_{8} \mathrm{O}_{7} \leftrightarrow 2 \mathrm{C}_{6} \mathrm{H}_{6} \mathrm{O}_{7}{ }^{2-}+4 \mathrm{H}^{+}$

If oxidized lead or copper forms are present, the following chemical reactions may occur:

$\mathrm{CuO}+\mathrm{C}_{6} \mathrm{H}_{8} \mathrm{O}_{7} \rightarrow \mathrm{Cu}^{2+}+\mathrm{C}_{6} \mathrm{H}_{6} \mathrm{O}_{7}^{2-}+\mathrm{H}_{2} \mathrm{O}$

$\mathrm{PbO}+\mathrm{C}_{6} \mathrm{H}_{8} \mathrm{O}_{7} \rightarrow \mathrm{Pb}^{2+}+\mathrm{C}_{6} \mathrm{H}_{6} \mathrm{O}_{7}^{2-}+\mathrm{H}_{2} \mathrm{O}$

which lead to copper and lead in the solution in an ionic form.<smiles>CC(=O)OC(C(=O)O)C(O)C(=O)O</smiles>

Fig. 1. The structural formula of a citric acid molecule.

The aim of this study was to investigate the use of citric acid as a leaching agent and optimize direct-to-blister copper flash smelting slag leaching conditions in such a way as to leach lead into the solution in the maximum extent, minimizing the degree of copper passage. The effects of parameters such as temperature, acid concentration, leaching time, solid/liquid (s/l) ratio in the lead and copper extraction were investigated and leaching conditions were optimized.

\section{Properties of examined material}

For research in this work, slag from the flash furnace of the Głogów II smelter was used. The analysis of the chemical composition of the slag used in all subsequent tests, carried out using the atomic absorption spectrometry (AAS), is presented in Table 1.

Tab. 1. Composition of the tested flash smelting slag. 


\begin{tabular}{|c|c|}
\hline component & content [\%] \\
\hline $\mathbf{N a}_{2} \mathbf{O}$ & 0.75 \\
\hline $\mathbf{K}_{2} \mathbf{O}$ & 2.39 \\
\hline $\mathbf{C a O}$ & 15.60 \\
\hline $\mathbf{M g O}$ & 4.94 \\
\hline $\mathbf{S i O}_{2}$ & 33.94 \\
\hline $\mathbf{A l}_{2} \mathbf{O}_{3}$ & 10.00 \\
\hline $\mathbf{F e O}$ & 10.23 \\
\hline $\mathbf{F e}_{2} \mathbf{O}_{3}$ & 12.81 \\
\hline $\mathbf{Z n O}$ & 1.40 \\
\hline $\mathbf{P b O}$ & 3.28 \\
\hline $\mathbf{C u O}$ & 15.58 \\
\hline
\end{tabular}

The content of lead and copper in the material used for the tests was $3.05 \%$ and $12.44 \%$, respectively.

The sieve analysis carried out showed that the slag is ground to less than $1 \mathrm{~mm}$. Slightly more than $50 \%$ by mass are grains with a size of $0.16 \div 0.32 \mathrm{~mm}$. The fraction of grains below $0.16 \mathrm{~mm}$ and above $0.32 \mathrm{~mm}$, which is about $24 \%$ by mass, is comparable. The slag being tested has only about $1.5 \%$ of the mass fraction with a relatively coarse grain size (grains above 0.63 $\mathrm{mm}$ ). The determination of the content of copper and lead was also carried out for individual fractions. Chemical analysis showed that in the grain size fraction above $0.63 \mathrm{~mm}$ there is a significant copper enrichment and a relatively lower percentage of lead in relation to the other fractions. The obtained analysis indicates the possibility of separating the grain size fraction $0.63 \div 1 \mathrm{~mm}$ from the remaining part of the slag, and then directing it directly to the flash furnace in order to recover the copper. The grain composition of the tested slag and the content of lead and copper in individual fractions are given in Table 2. Figure 2 shows the dependence of the cumulative fraction on the grain size.

Tab. 2. Results of sieve analysis and $\mathrm{Cu}$ and $\mathrm{Pb}$ content in individual fractions.

\begin{tabular}{|c|c|c|c|}
\hline $\begin{array}{c}\text { diameter of } \\
\text { grains [mm] }\end{array}$ & $\begin{array}{c}\text { mass fraction } \\
{[\%]}\end{array}$ & $\mathbf{C u}[\%]$ & Pb [\%] \\
\hline $\mathbf{1 . 0 0} \div \mathbf{0 . 6 3}$ & 1.56 & 46.2 & 1.95 \\
\hline $\mathbf{0 . 6 3} \div \mathbf{0 . 3 2}$ & 22.61 & 15.2 & 3.02 \\
\hline $\mathbf{0 . 3 2} \div \mathbf{0 . 1 6}$ & 51.89 & 12.1 & 2.96 \\
\hline $\mathbf{0 . 1 6} \div \mathbf{0 . 1 0}$ & 13.71 & 10.2 & 2.96 \\
\hline $\mathbf{0 . 1 0} \div \mathbf{0 . 0 7 1}$ & 9.41 & 10.7 & 3.49 \\
\hline $\mathbf{0 . 0 7 1} \div \mathbf{0 . 0 5 6}$ & 0.38 & 11.5 & 3.50 \\
\hline $\mathbf{0 . 0 5 6} \div \mathbf{0}$ & 0.45 & 15.6 & 3.4 \\
\hline
\end{tabular}




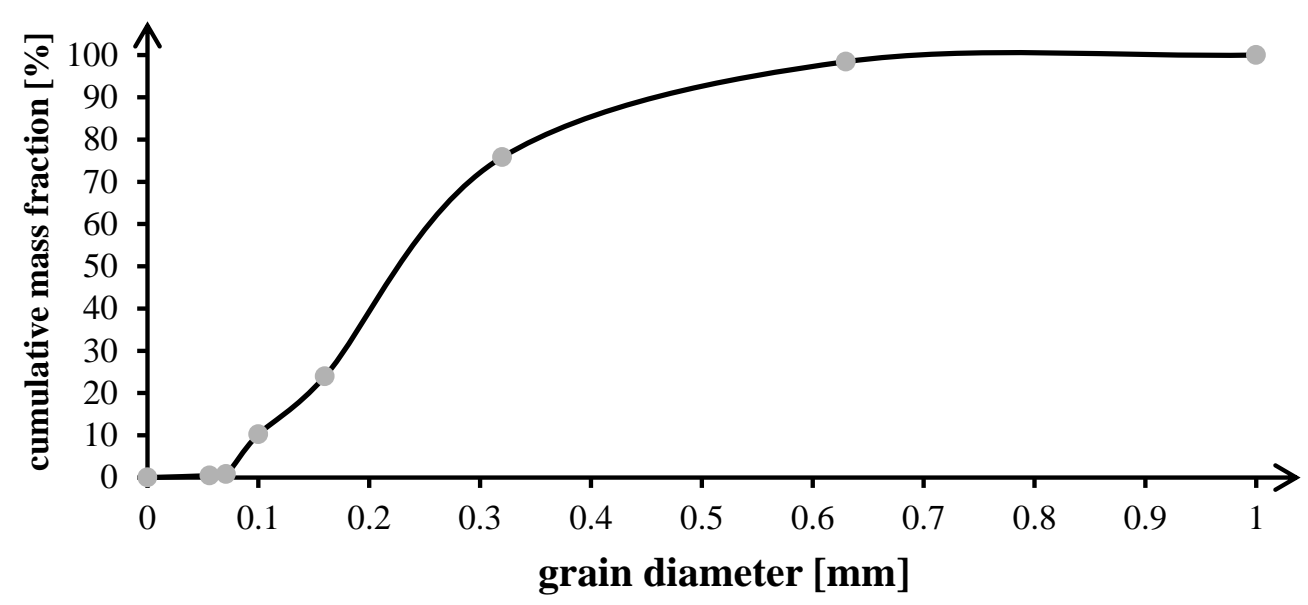

Fig. 2. The dependence of cumulative mass fraction on the size of grains.

Proper selection of the leaching factor requires a detailed specification of the specificity of the leached material. The form of occurrence in which the metal that we want to leach is very important. For this purpose, identification of the phase composition of the flash smelting slag under investigation using the XRD method was carried out. X-ray analysis showed that lead is only in oxidized form as $\mathrm{PbO}$. The copper is present in the slag in a metallic form and in a significant amount in the form of an oxide phase with a composition similar to $\mathrm{Cu}_{2} \mathrm{O}$. Analysis of the XRD pattern also revealed the occurrence of copper to a lesser extent in the form of an oxide copper and iron compound with the formula $\mathrm{CuFeO}_{2}$. The results of $\mathrm{X}$-ray analysis are shown in Figure 3.

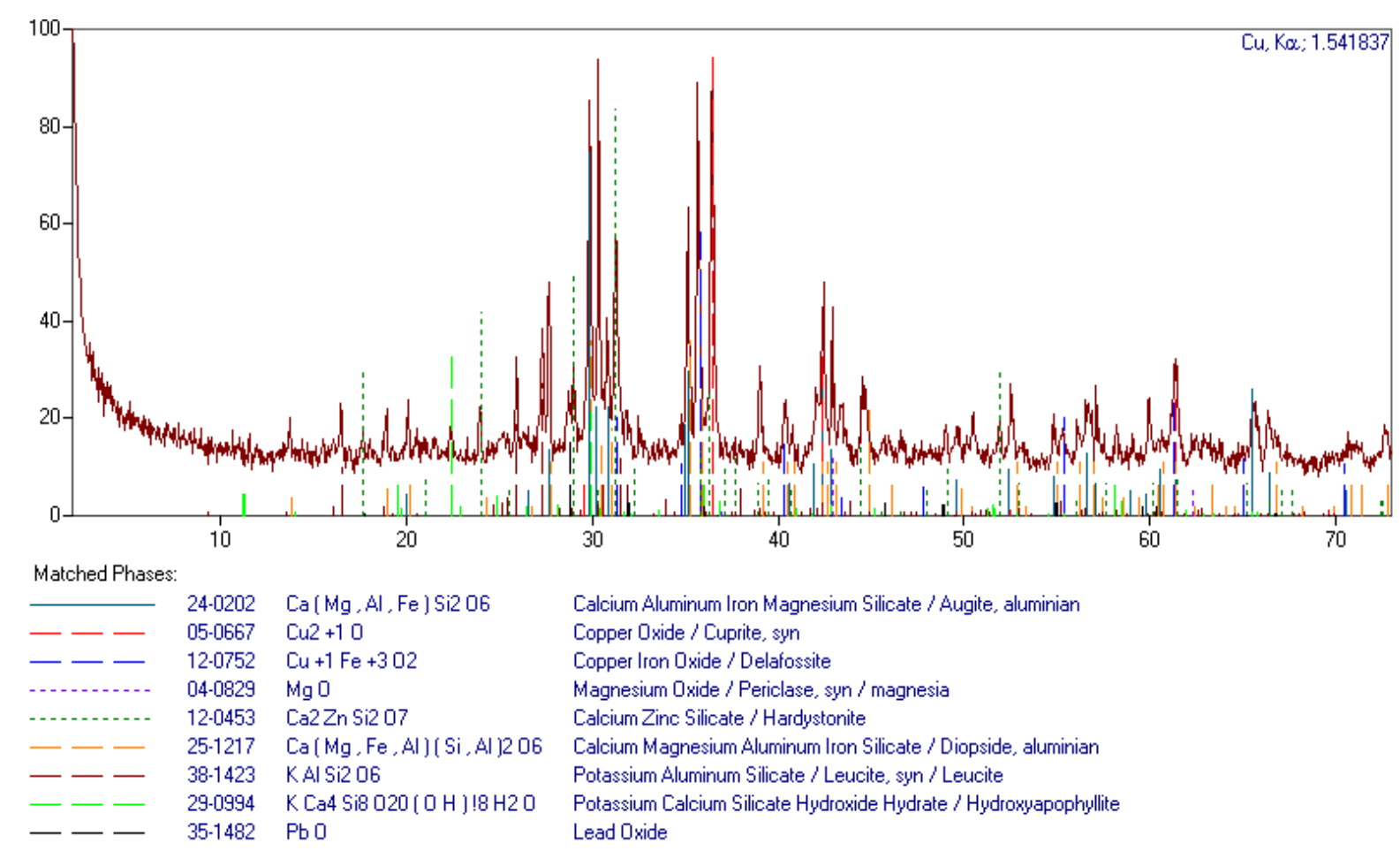

Fig. 3. XRD pattern of the flash smelting slag sample. 
In this work, analyzes of the chemical composition and flash smelting slag microstructure were also performed. The scanning electron microscope equipped with a spectrometer with X-ray energy dispersion (SEM-EDS) was used. The SEM image obtained for the average sample of slag and the EDS analysis result showing the occurrence of specific elements on the whole surface of this image are presented in Figure 4. Points 1, 2 and 3 are marked on specific microscopic structures from this area, which have a different chemical composition from the average composition of the entire surface of the test sample. For individual micro-areas, EDS analysis was performed, which is shown in Figure 5. EDS spectra from points 1 and 2, and in particular 3 show the occurrence of $\mathrm{Pb}, \mathrm{Si}$ and $\mathrm{O}$, and therefore it can be assumed that lead in addition to being in the form of $\mathrm{PbO}$ (XRD analysis) may also appear in silicate form.
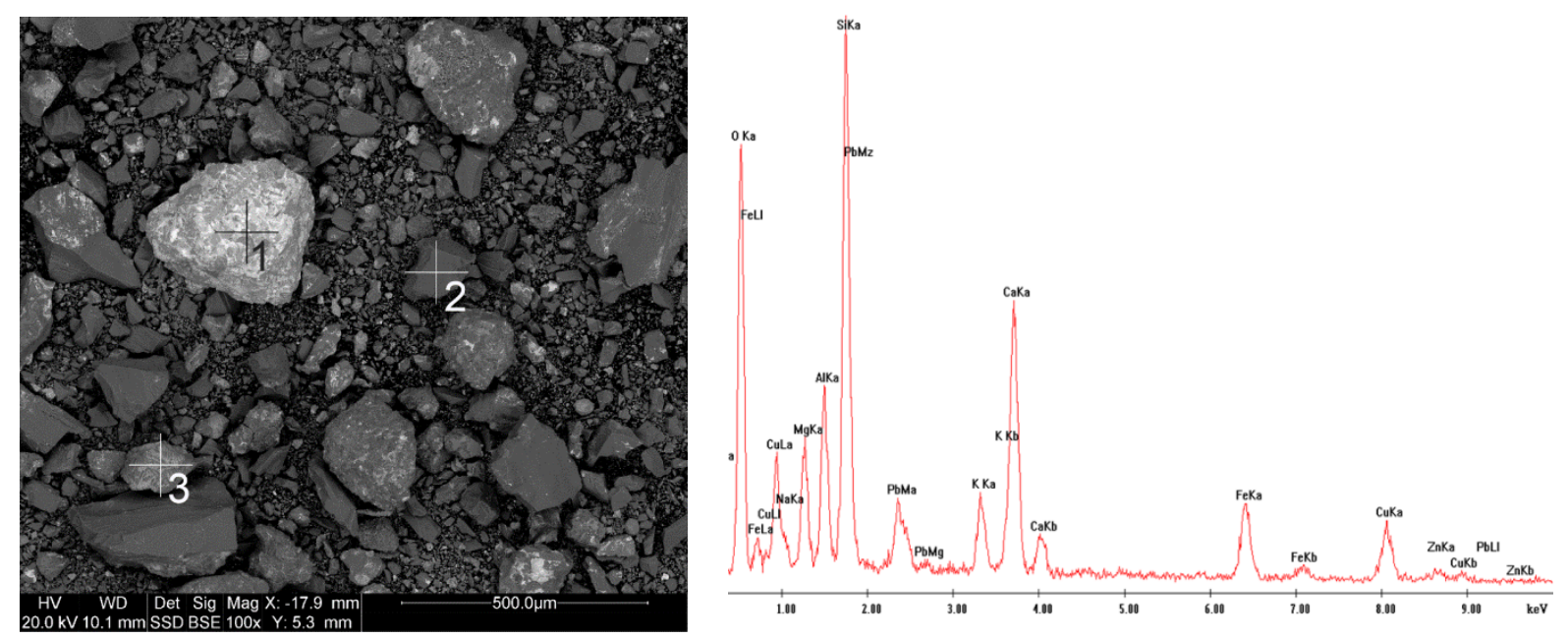

Fig. 4. The microscopic image of the average sample of slag and EDS analysis of this area. 
point 1)

point 2)
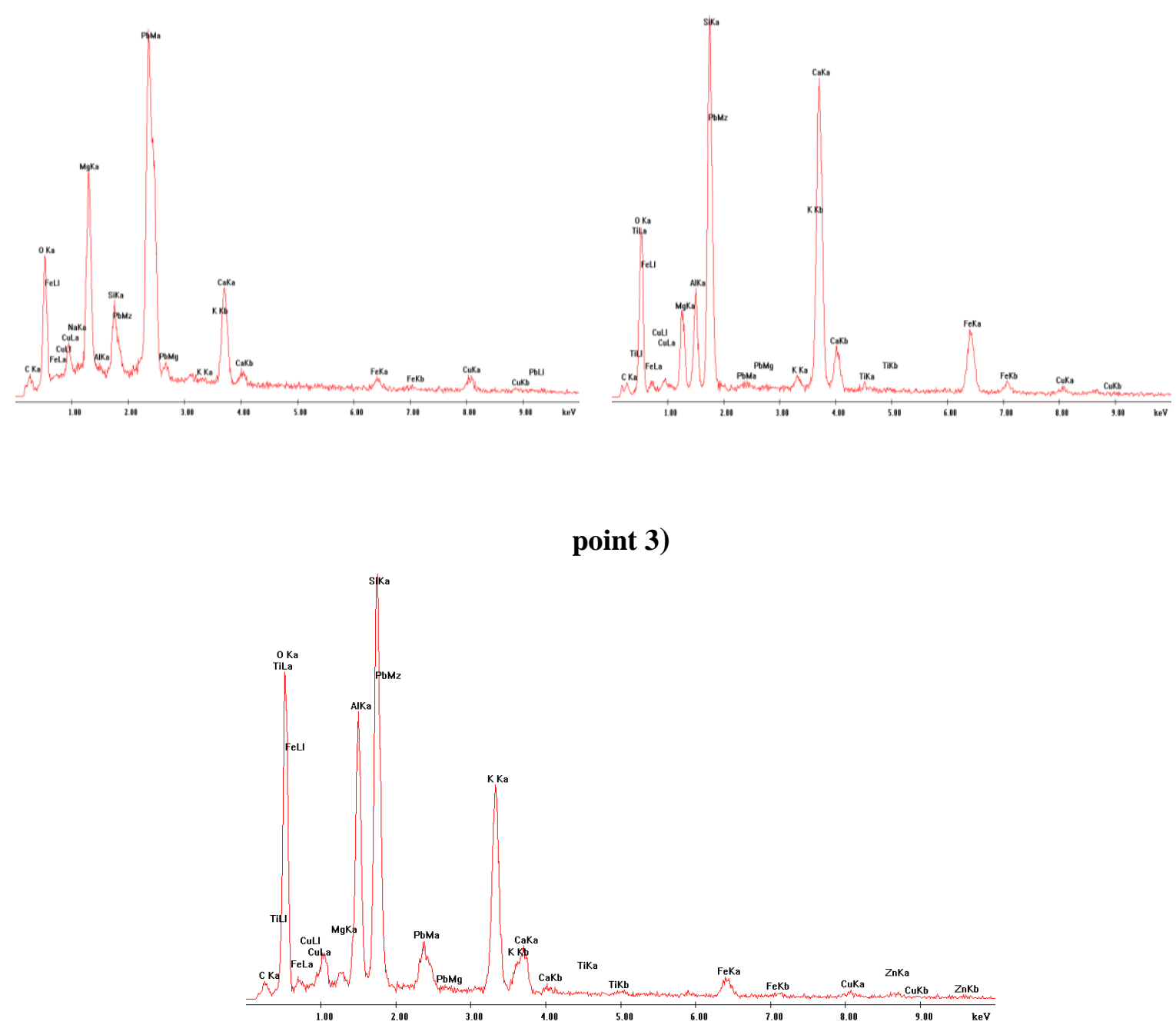

Fig. 5. EDS analysis of point 1, 2 and 3.

\section{Hydrometallurgical processing of direct-to-blister copper flash smelting slag}

\subsection{Experimental procedure of hydrometallurgical processing}

The conditions of the leaching process was examined by changing the temperature, time, concentration of the citric acid solution and the mass ratio of the liquid phase to the solid phase $(1 / s)$. The leaching solutions of a given concentration were prepared from distilled water and citric acid ( $\geq 99.5 \%$, Merck). Appropriate volumes of the prepared solution were metered and poured into the vessel in which the slag leaching was carried out. The vessel was placed in a measuring system and the solution was heated to a fixed temperature using a heating plate. Next, the slag of constant mass (20 g) was prepared, and after the solution had obtained the planned temperature, a slag sample was added and the mechanical stirrer was started, leading the process for a fixed time. Each experiment was carried out at a constant stirring speed (300 rpm) to allow the slag to be lifted in the solution. After the leaching was completed, the slurry was filtered, and the resulting precipitate was washed with distilled water, dried and weighed. The slag remaining after leaching was subjected to chemical analysis by atomic absorption spectrometry (AAS) to determine the content of lead and copper. For all performed tests, the 
leaching efficiency of lead and copper from slag was determined, which was calculated according to the following equation:

$\mathrm{n}_{M}=\frac{m_{M, o}-m_{M, f}}{m_{M, o}} \cdot 100[\%]$

where:

$\mathrm{M}=\mathrm{Pb}, \mathrm{Cu}$

$\mathrm{n}_{\mathrm{M}}$ - leaching efficiency of $\mathrm{M}$

$\mathrm{m}_{\mathrm{M}, \mathrm{o}}-$ mass of $\mathrm{M}$ in the slag before leaching, $m_{M, o}=\%_{M, o} \cdot m_{s, o}$

$\% \mathrm{M}, \mathrm{o}-$ the percentage of $\mathrm{M}$ in the slag before leaching

$\mathrm{m}_{\mathrm{s}, \mathrm{o}}-$ mass of slag before leaching $(20 \mathrm{~g})$

$\mathrm{m}_{\mathrm{M}, \mathrm{f}}-$ mass of $\mathrm{M}$ in the slag after leaching, $m_{M, f}=\%_{M, f} \cdot m_{s, f}$

$\%_{\mathrm{M}, \mathrm{f}}$ - the percentage of $\mathrm{M}$ in the slag after leaching

$\mathrm{m}_{\mathrm{s}, \mathrm{f}}-$ mass of slag after leaching

\subsection{Results and discussion of hydrometallurgical tests}

In the first place, tests were carried out on the effect of the concentration of citric acid in the leaching solution on the concentration of lead and copper in the slag samples after leaching for three different process temperatures $\left(25^{\circ} \mathrm{C}, 50^{\circ} \mathrm{C}, 70^{\circ} \mathrm{C}\right)$. The process time was 15 minutes and the mass ratio of the liquid phase to the solid phase was 10 . The results obtained in this series of tests are shown in Fig. 6 (concentrations of metals) and Fig. 7 (leaching efficiency of lead and copper). The obtained results indicate that the highest decrease in lead concentration in the leaching sample is noted in the case of a leaching solution containing citric acid in a concentration of $1 \mathrm{~mol} / \mathrm{dm}^{3}$ at a temperature of $70^{\circ} \mathrm{C}$. At the same time, a relatively low drop in the concentration of copper in the material after leaching can be observed in these conditions. Almost $90 \%$ of lead and $30 \%$ of the copper contained in the slag passes under those conditions to the solution. Considering the above facts, the next stage of testing was carried out in the conditions of a fixed concentration of citric acid in the solution at the level of $1 \mathrm{~mol} / \mathrm{dm}^{3}$, at two temperatures $\left(25^{\circ} \mathrm{C}\right.$ and $\left.70^{\circ} \mathrm{C}\right)$, with a ratio s/l of 10 , differentiating the leaching time from 15 to 45 minutes. The results of the tests are presented in Fig. 8 and 9.
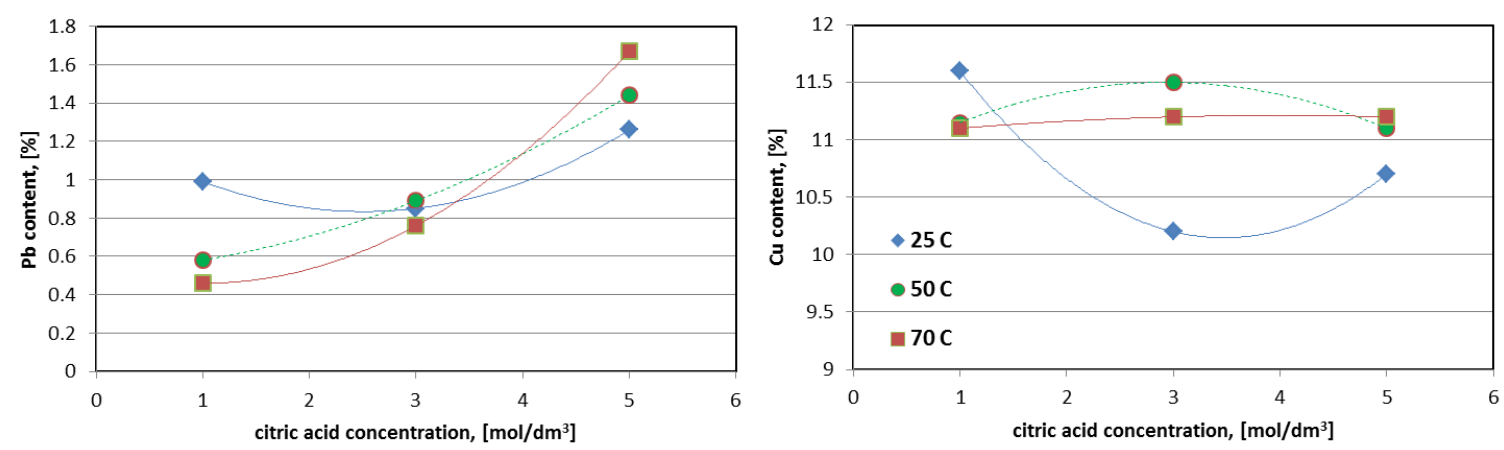

Fig. 6. The content of lead and copper in samples after leaching depending on the concentration of citric acid $(t=15 \mathrm{~min}, \mathrm{l} / \mathrm{s}=10)$. 

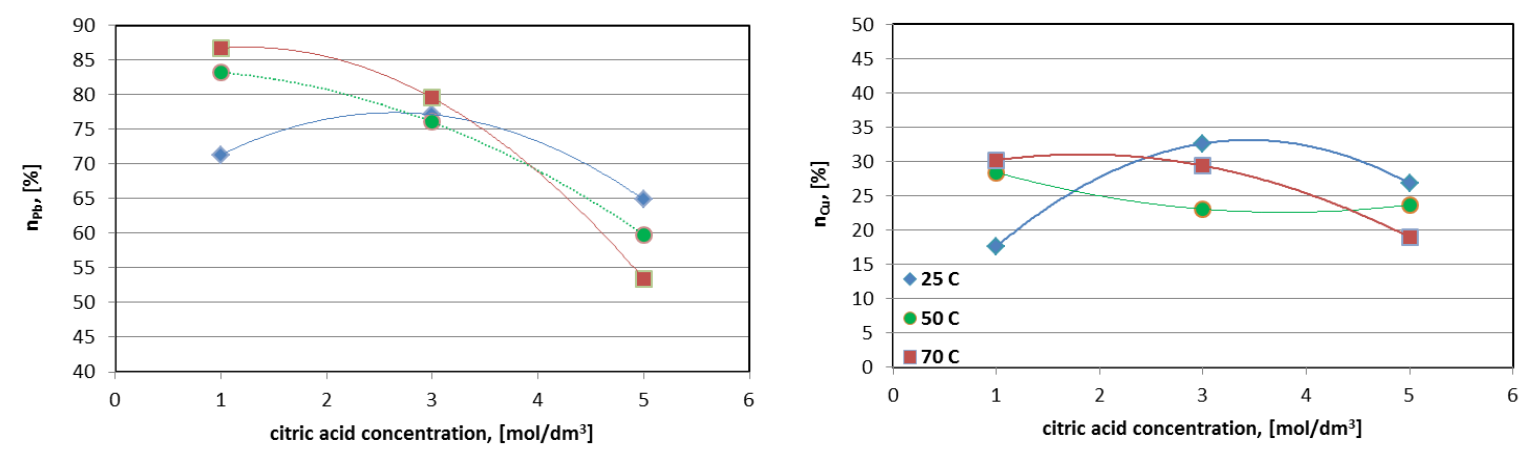

Fig. 7. Leaching efficiency of lead and copper from slag depending on the concentration of citric acid $(\mathrm{t}=15 \mathrm{~min}, 1 / \mathrm{s}=10)$.
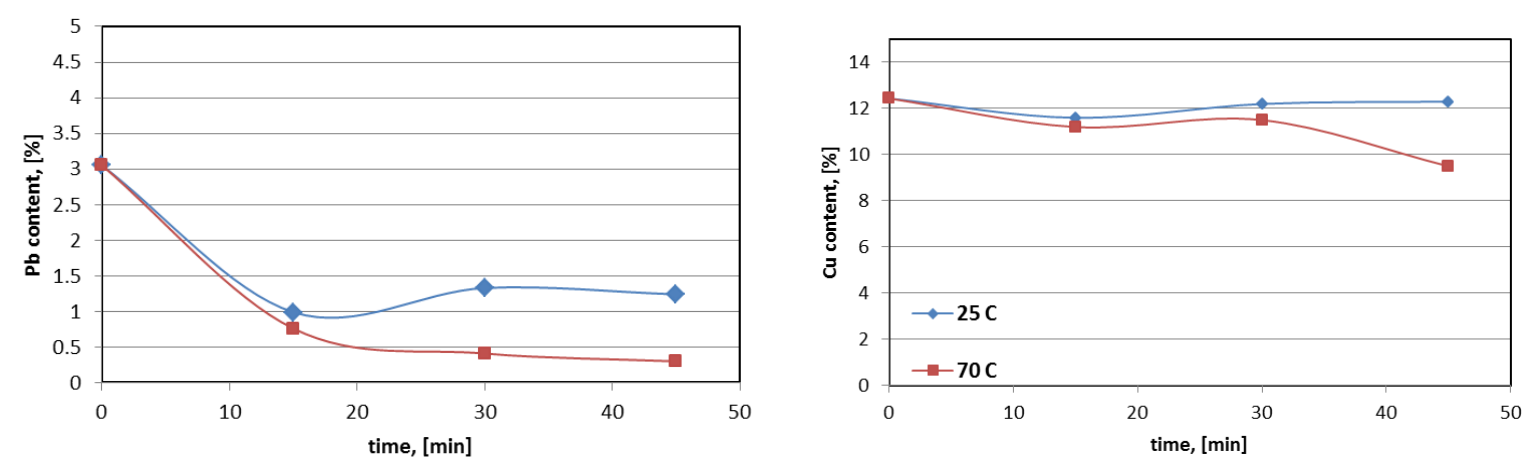

Fig. 8. The content of lead and copper in samples after leaching depending on the time of the process $\left(1 \mathrm{~mol} / \mathrm{dm}^{3}\right.$ citric acid, $\left.1 / \mathrm{s}=10\right)$.
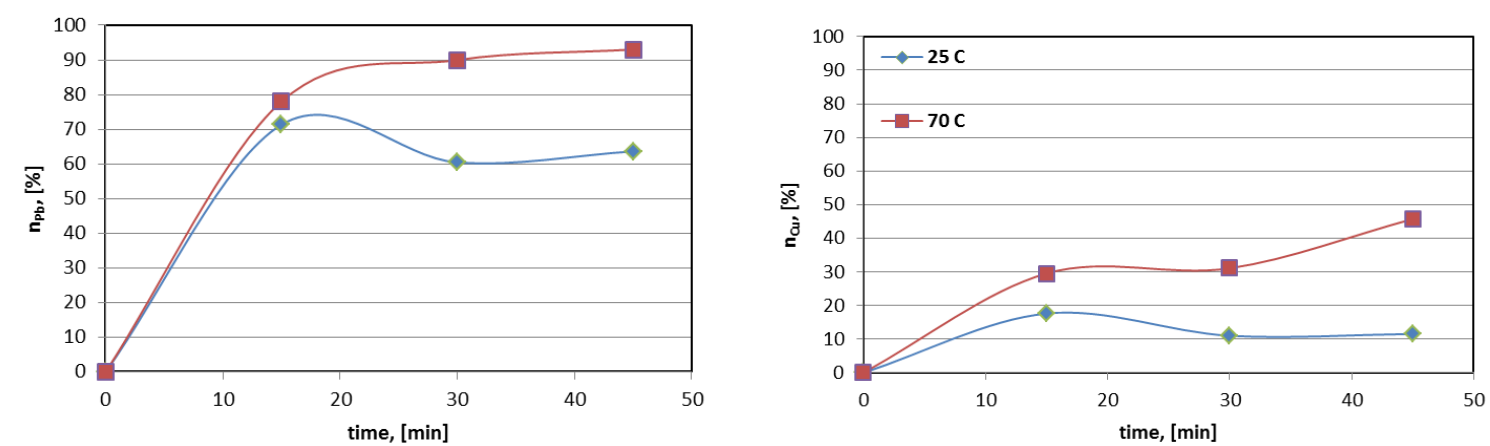

Fig. 9. Leaching efficiency of lead and copper from slag depending on the time of the process $\left(1 \mathrm{~mol} / \mathrm{dm}^{3}\right.$ citric acid, $\left.1 / \mathrm{s}=10\right)$.

It can be noticed that at $70^{\circ} \mathrm{C}$, the process time has an inverse proportion to the $\mathrm{Pb}$ content in the leach residue. So the longer the less lead in the slag after the process. The situation is different in relation to copper. In the conditions described above, the highest content of copper in the slag after the process can be observed after about 30 minutes of leaching. Since the proposed process of hydrometallurgical processing is to maximize the removal of lead from the slag with minimal the passage of copper to the solution, it was assumed that the optimal time from this point of view would be a process time of just 30 minutes.

The last series of tests performed was to determine the impact of the mass ratio of the leaching solution to the slag (1/s) on the lead and copper transition process into the solution. The tests were carried out for 2 different temperatures $\left(25^{\circ} \mathrm{C}\right.$ and $\left.70^{\circ} \mathrm{C}\right)$, in the conditions of a 
fixed concentration of citric acid in the solution at the level of $1 \mathrm{~mol} / \mathrm{dm}^{3}$ during 30 minutes. Figures 10 and 11 present the results obtained after the leaching tests. It can be clearly seen that from the point of view of reducing the $\mathrm{Pb}$ content in the slag after leaching, the optimal $1 / \mathrm{s}$ ratio is the value of $10(0.41 \% \mathrm{~Pb}, 11.5 \% \mathrm{Cu}$ in the leaching residue $)$ at a temperature of $70^{\circ} \mathrm{C}$. Considering two factors, i.e. lowering the lead content and minimizing the degree of copper passage into the solution, the desired value of $1 / \mathrm{s}$ may seem to be 5 . At $70^{\circ} \mathrm{C}$ and at $1 / \mathrm{s}=5$, a sufficiently low content of $\mathrm{Pb}$ from slag after leaching can be noted $(0.6 \%)$ and higher than in the previous case copper content $(11.8 \%)$.
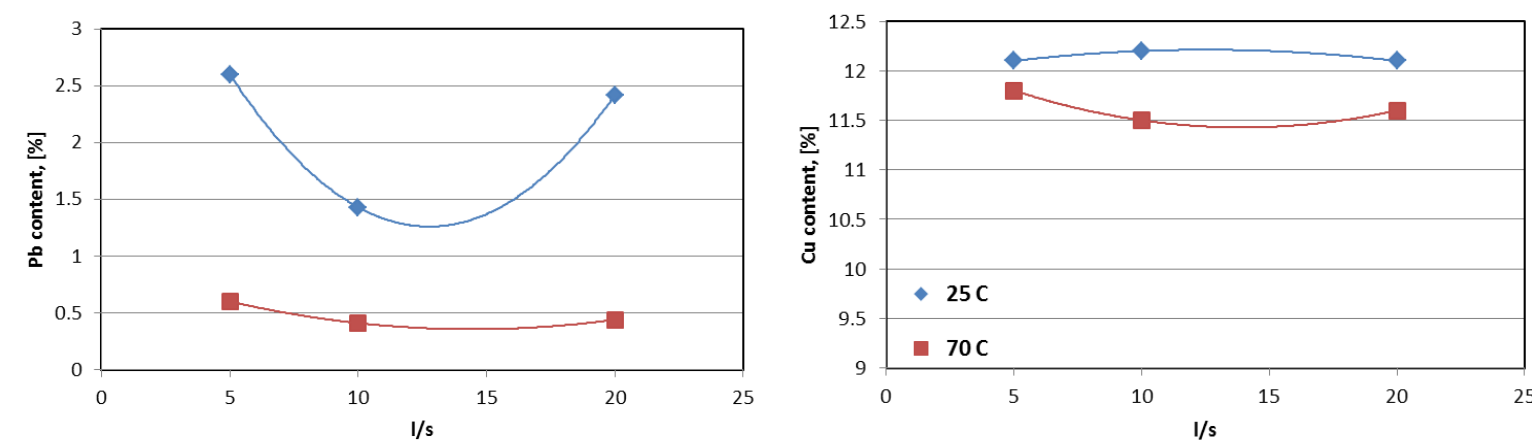

Fig. 10. The content of lead and copper in samples after leaching depending on the $1 / \mathrm{s}$ ratio $\left(1 \mathrm{~mol} / \mathrm{dm}^{3}\right.$ citric acid, $\left.\mathrm{t}=30 \mathrm{~min}\right)$.
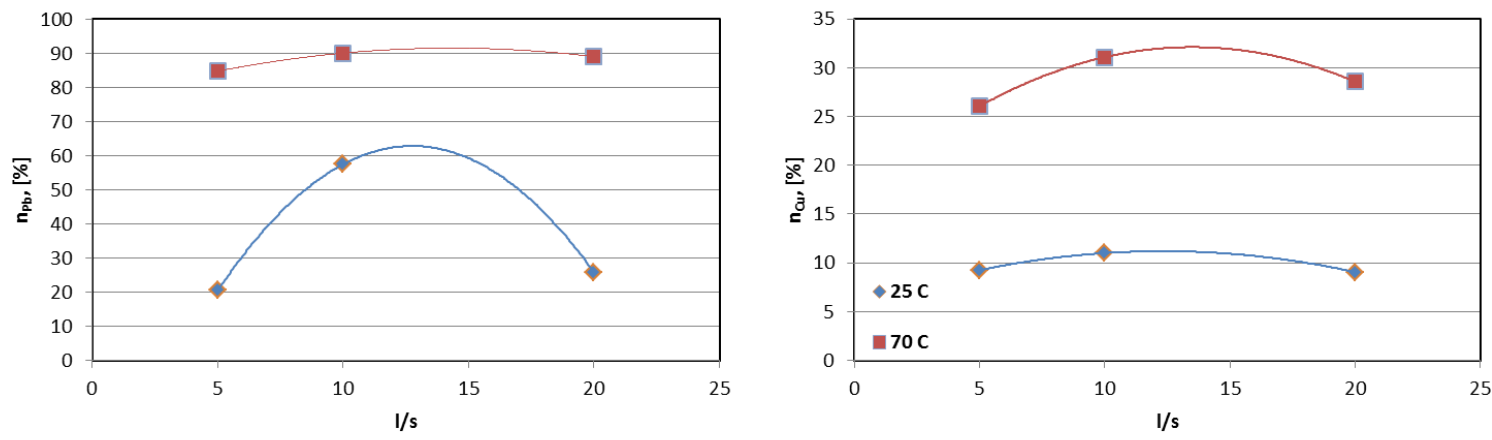

Fig. 11. Leaching efficiency of lead and copper from slag depending on the $1 / \mathrm{s}$ ratio $\left(1 \mathrm{~mol} / \mathrm{dm}^{3}\right.$ citric acid, $\left.\mathrm{t}=30 \mathrm{~min}\right)$.

Achieving the aim of testing, which was the maximum lead transfer from slag to solution with a minimal passage of copper to the solution is obtained in the following conditions: $1 \mathrm{~mol} / \mathrm{dm}^{3}$ of citric acid, 30 minutes, $70^{\circ} \mathrm{C}, 1 / \mathrm{s}=5$. Concentration of metals in the leaching residues was then: $0.6 \% \mathrm{~Pb}$ and $11.8 \% \mathrm{Cu}$. Leaching efficiency of lead and copper was $84.67 \%$ and $26.06 \%$ respectively.

\section{Conclusions}

Performed tests confirm the possibility of using citric acid solutions for the hydrometallurgical processing of flash smelting slag containing lead and copper. During the research, the influence of different leaching parameters on the degree of lead and copper transition to the solution was observed. The purpose of this work was to determine the conditions under which the lead leaching process takes place and the passage of copper to the solution is minimal. The obtained results indicate that it is possible to lead the process so that about $85 \%$ of the lead contained in the slag passes into the solution, and only slightly over $26 \%$ 
of the copper was leached out under these conditions. The leaching solution can be further regenerated using sulfuric acid with $\mathrm{PbSO}_{4}$ precipitation and used in a closed loop in the slag leaching process until saturation with copper. In this case, purification of the solution can be carried out by electrolysis and obtaining cathodic copper as the final product. The solid residue obtained after the citric acid leaching process can be processed in the next step using $\mathrm{H}_{2} \mathrm{SO}_{4}$ solutions, which should lead to a high recovery rate of copper and to receive final material with low content of both lead and copper.

Acknowledgments: This paper is supported by the Ministry of Science and Higher Education (Grant No. 11.11.180.726).

\section{References}

1. N. Habbache, N. Alane, S. Djerad, and L. Tifouti, Leaching of copper oxide with different acid solutions, Chem. Eng. J., 152(2009), p.503.

2. F. Demir and B. Dönmez, Optimization of the dissolution of magnesite in citric acid solutions, Int. J. Miner. Process., 87(2008), p.60.

3. R. Zárate-Gutiérrez, L. Gregorio-Vázquez \& G. T. Lapidus (2015) Selective leaching of lead from a lead-silver-zinc concentrate with hydrogen peroxide in citrate solutions, Canadian Metallurgical Quarterly, 54:3, 305-309.

4. M.A. Shabani, M. Irannajad, and A.R. Azadmehr, Investigation on leaching of malachite by citric acid, International Journal of Minerals, Metallurgy and Materials, vol. 19, nr. 9, 2012, p.782.

5. U.U. Jadhav, H. Hocheng, A review of recovery of metals from industrial waste, Journal of Achievements in Materials and Manufacturing Engineering 54/2 (2012) 159-167.

6. Jyh-Herng Chen and Chien-Er Huang, Selective Separation of $\mathrm{Cu}$ and $\mathrm{Zn}$ in the Citric Acid Leachate of Industrial Printed Wiring Board Sludge by D2EHPA-Modified Amberlite XAD-4 Resin, Ind. Eng. Chem. Res. 2007, 46, 7231-7238.

7. Vojtech Ettler, Marie Komarkova, Jan Jehlicka, Pavel Coufal, David Hradil, Vladimır Machovic, Fabian Delorme, Leaching of lead metallurgical slag in citric solutions implications for disposal and weathering in soil environments, Chemosphere 57 (2004) 567-577.

8. Pratima Meshram, Lalit Bhagat, Uday Prakash, Banshi Dhar Pandey \& Abhilash (2017): Organic acid leaching of base metals from copper granulated slag and evaluation of mechanism, Canadian Metallurgical Quarterly, DOI: 10.1080/00084433.2017.1293900

9. M.S. Sonmez, R.V. Kumar, Leaching of waste battery paste components. Part 1: Lead citrate synthesis from $\mathrm{PbO}$ and $\mathrm{PbO}_{2}$, Hydrometallurgy 95 (2009) 53-60.

10. M.S. Sonmez, R.V. Kumar, Leaching of waste battery paste components. Part 2: Leaching and desulphurisation of $\mathrm{PbSO}_{4}$ by citric acid and sodium citrate solution, Hydrometallurgy 95 (2009) 82-86.

11. Chung-Hsin Wu, Chao-Yin Kuo, Shang-Lien Lo, Removal of Metals from Industrial Sludge by Extraction with Different Acids, Journal of Environmental Science and Health Part A-Toxic/Hazardous Substances \& Environmental Engineering, Vol. A39, No. 8, pp. 2205-2219, 2004.

12. Gergoric, M.; Ravaux, C.; Steenari, B.-M.; Espegren, F.; Retegan, T. Leaching and Recovery of Rare-Earth Elements from Neodymium Magnet Waste Using Organic Acids. Metals 2018, 8, 721. 
13. D. del Mundo Dacera, S. Babel, Use of citric acid for heavy metals extraction from contaminated sewage sludge for land application, Water Science \& Technology, Vol. 54, No 9, pp. 129-135, 2006.

14. Hongki Park, Kyungbae Jung, Richard Diaz Alorro, Kyoungkeun Yoo, Leaching Behavior of Copper, Zinc and Lead from Contaminated Soil with Citric Acid, Materials Transactions, Vol. 54, No. 7 (2013) pp. 1220-1223.

15. Raman Bassi, Shiv O. Prosher, Extradon of Metab from a Contaminated Sandy Soil Using Citric Acid, Environmental Progress, vol.19, No.4, 2000, pp. 275-282.

16. Kai Huang, Katsutoshi Inoue, Hiroyuki Harada, Hidetaka Kawakita, Keisuke Ohto, Leaching of heavy metals by citric acid from fly ash generated in municipal waste incineration plants, J Mater Cycles Waste Manag, (2011) 13:118-126. 